\title{
Compressive strength of lightweight expanded polystyrene basalt fiber concrete
}

\author{
Galina Okolnikova, Lina Abass Saad, Majeed M. Haidar, and Fouad adnan noman \\ Abdullah Al-shaibani* \\ Department of Civil Engineering, Peoples Friendship University of Russia (RUDN University), 6 \\ Miklukho - Maklaya Street, Moscow, 117198, Russian Federation
}

\begin{abstract}
The ability of concrete to give a lower weight and retain good properties for strength is very important concrete structures. Lightweight concrete is known for its brittleness hence the strengthening of the concrete with dispersed chopped fiber is necessary. The addition of dispersed chopped fiber in polystyrene concrete to check the effect of the fiber this concrete the main objective of this paper. The experimental method of research was used in this research paper after a proper review of previous works by other researchers were done. 42 grams of fiber were added in the concrete mix of each composition. The results of this research show a noticeable effect of fiber in the lightweight expanded polystyrene concrete. The concrete without fiber showed the best compressive strength followed by the concrete with dispersed polypropylene fiber.
\end{abstract}

\section{Introduction}

For more than fifty years, there have been attempts to overcome the drawbacks of concrete. Concrete is a structural material with properties like very heavy, rigid and its thermal and acoustical qualities are not very high. Much research has been done to replace aggregates of concrete, sand, and gravel with lighter materials. It was stated that corn, pumice, schist, cork, pozzolana, and woods (scraps or sawdust) were the first natural products utilized in concrete. Later, with greater knowledge and insulation concerns more materials were used including expanded clay, vermiculite, expanded glass, aluminium, expanded rock, and expanded polystyrene (EPS) (see fig. 1) [1].

Concrete is known as the most used material in the construction industry, and it is also a huge consumer of natural resources. Concrete mix containing waste materials are beneficial in protecting the environment [2-4]. Waste materials such as polystyrene, cork, tire, are mostly used as components of building materials because the properties they possess like the thermal and acoustical properties [5-8]. Studies involving concrete-related topics approach different types of building materials with polystyrene granule, such as mortar, concrete, pavement, etc. Effects of polystyrene granule in concrete depend on its type (cement-based concrete or polymer-based concrete), dosage and type of polystyrene, etc.

* Corresponding author: fouad.alshaibani@yandex.ru 


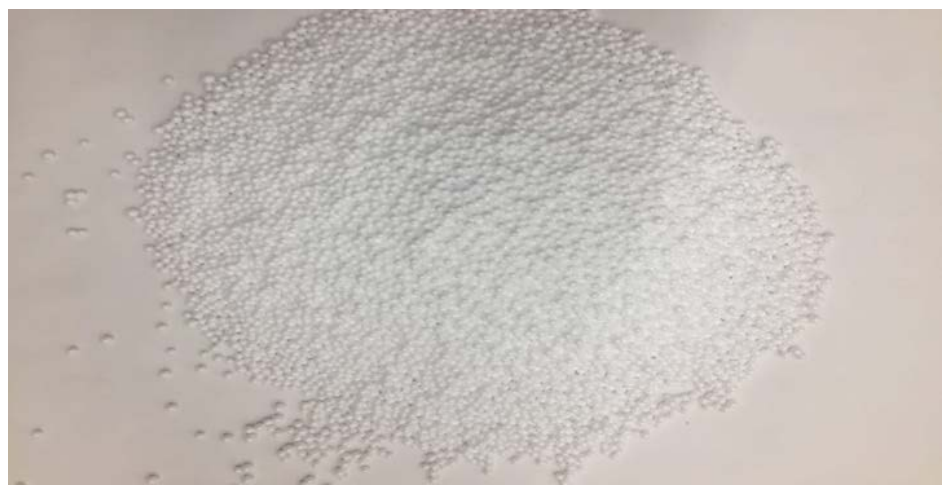

Fig. 1. Expanded polystyrene

In most cases, increasing of polystyrene dosage will be followed by a decreasing of its mechanical characteristics. Some experiments showed that the thermal treatment of polystyrene improves the behaviour of concrete, respectively the characteristics that are related to workability, density, thermal conductivity, and shrinkage [9]. A different type of polystyrene treatment consisting in coating the granules was used for obtaining some concrete in which mineral aggregates were replaced with polystyrene [10,11]. In this case, the authors studied the creep of concrete and found that it is higher than that of ordinary concrete.

Concrete analysis conducted severally found that when polystyrene granules are used as ingredients in concrete with natural resin with the increasing of polystyrene, the density, thermal conductivity, compressive and tensile strength decrease while porosity increases [12]. Addition, of polymer in polystyrene concrete (PSC) gives better compressive and flexural strength than concrete with polystyrene without polymer [13]. When fly ash is used as cementitious material in concrete with polystyrene granules, compressive strength, tensile strength, and secant modulus decrease with increasing polystyrene dosage $[14,15]$.

Lightweight concretes (LWC) have been successfully used in the construction, thanks to its low density. PSC, with density from about $500 \mathrm{~kg} / \mathrm{m}^{3}$ to $900 \mathrm{~kg} / \mathrm{m}^{3}$, is being used in nonstructural applications, has been studied and applied in many projects. PSC also can be manufactured with higher density and strength to meet the requirements of concrete for structural application. However, until now the structural LWC using EPS aggregate is not specified in standard [16].

Based on number of studies [17, 18], non-structural PSC element have been carried out to produce no-structural element in factor, with density from about $500 \mathrm{~kg} / \mathrm{m}^{3}$ to $900 \mathrm{~kg} / \mathrm{m}^{3}$ and compressive from 2.5 MPa to 5.0 MPa. Moreover, PSC also can be used to produce monolithic structures on construction site. This is a great advantage over autoclaved aerated concrete or foam concrete. Further, by varying the amount of EPS, the density of PSC can be adjusted from $450 \mathrm{~kg} / \mathrm{m}^{3}$ to $2,000 \mathrm{~kg} / \mathrm{m}^{3}[19,20]$. Both EPS beads and polystyrene waste can be used as aggregates [21]. Using mineral admixtures, such as fly ash [21-23], silica fume [20], rice husk ash [24], nano silica fume [25], improved durability, performance, and reduced porosity of PSC. But it also effects on workability of mixture. So, studies [24, 26] used water reducing admixtures in mix designs.

The previous studies $[20,26,27]$ indicated that EPS particle size affected properties of PSC, particularly compressive strength. EPS with diameter from $1 \mathrm{~mm}$ to $2.5 \mathrm{~mm}$ is less likely to affect the compressive strength of concrete [26]. Thus, using this EPS 's particle size does not significantly affect compressive strength of PSC with equal density from 1,400 $\mathrm{kg} / \mathrm{m}^{3}$ to $2,000 \mathrm{~kg} / \mathrm{m}^{3}$. 
From the above review, this paper aims to analyse the effect of FRP in LWC containing polystyrene granules as a substitute for aggregate. The compressive strength will be compared. The replacement of mineral aggregates and cement is used to obtain a lightweight concrete.

\section{Materials and methods of experiment}

This lightweight expanded polystyrene basalt fiber concrete comprises of the materials listed below in its concrete mix.

- Cement as binder $4.78 \mathrm{~kg}$

- Quartz sand as fine aggregate $3.15 \mathrm{~kg}$

- Polystyrene granules as main aggregate $0.075 \mathrm{~kg}$ (see fig. 1)

- Water 1.85 liters

- Hard chopped basalt fiber of diameter 1 milli meter $=42$ grams (see fig. 2)

- Soft chopped basalt fiber of diameter 15 micro meter $=42$ grams (see fig. 3 )

- Polypropylene fiber diameter 15 micro meter $=42$ grams (see fig. 4 )

A total of 6 (six) lightweight expanded polystyrene concrete mix are made for the work. 9 (nine) concrete cubes were made from each mix.

The compressive strengths were testing on concrete cubes of dimensions $100 \mathrm{~mm} \times 100 \mathrm{~mm}$ $\mathrm{x} 100 \mathrm{~mm}$. The cubes are molded in a metallic form. The concrete cubes are molded according CIS Interstate Standard GOST 10180-2012 [28]. After pouring the LWC in the molds, the molds were covered with polytelin and kept at room temperature $(20 \pm 5){ }^{\circ} \mathrm{C}$ and relative air humidity $(95 \pm 5) \%$. On the 48th hour, the LWC cubes were removed from the molds (fig. 5 ) and kept in the curing cupboard till the 28th day then the cubes were tested for compressive strength on a Matest Universal Testing Maching (fig. 6).

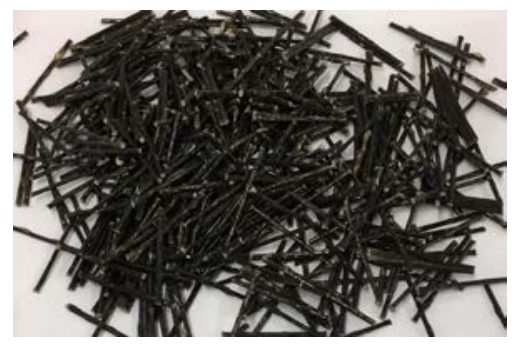

Fig. 2. Hard chopped basalt fiber

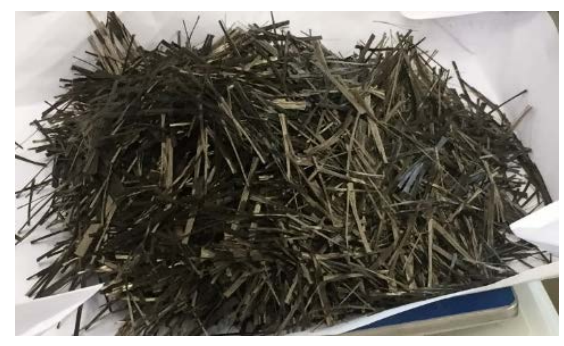

Fig. 3 Soft chopped basalt fiber

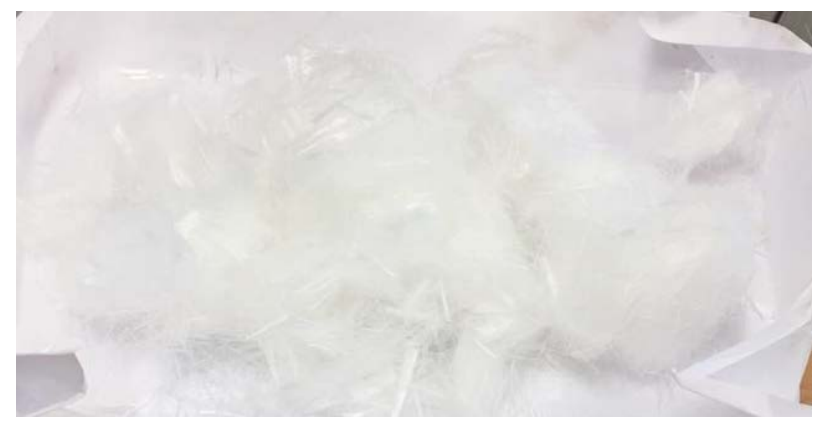

Fig. 4. Polypropylene fiber 


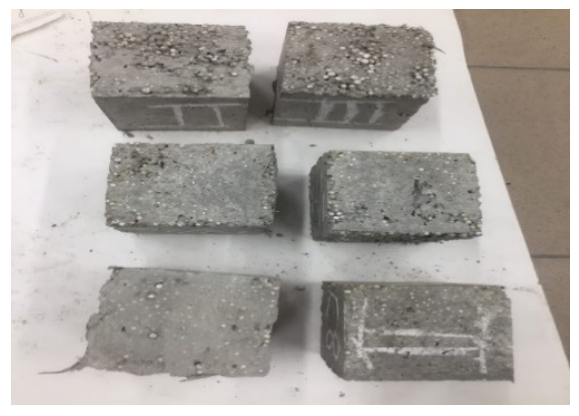

Fig. 5. Lightweight expanded polystyrene concrete

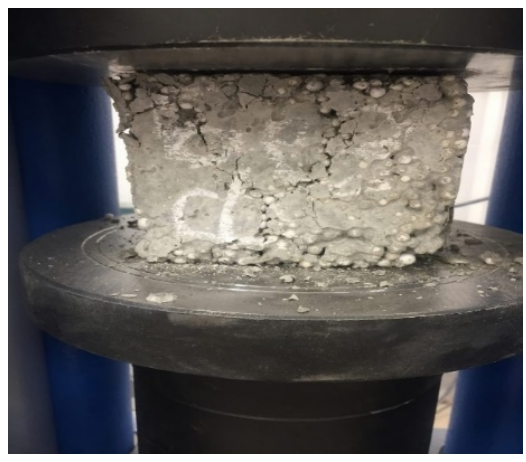

Fig. 6. Compressive test on Matest Universal Testing Machine

\section{Results and discussions}

The results shown in table 1 average from the 9 concrete cube specimens from each of the concrete mix. The compressive strength tests were done on the 28th day curing period. Table 1 and Fig. 7 shows the experimental results of the research work. An influence of fiber dimension, texture and type is seen in the results. Lightweight expanded polystyrene concrete (LWEPSC) without fiber shows better compressive strength than the LWEPSC with dispersed fibers.

Table 1. Results of Lightweight expanded polystyrene concrete (LWEPSC) experiments

\begin{tabular}{|c|c|c|}
\hline $\begin{array}{c}\text { Lightweight expanded polystyrene } \\
\text { concrete (LWEPSC) with }\end{array}$ & $\begin{array}{c}\text { Average weight, } \\
\text { grams }\end{array}$ & $\begin{array}{c}\text { Compressive } \\
\text { Strength, MPa }\end{array}$ \\
\hline $\begin{array}{c}\text { Basalt fiber of length 30-31 MM. (hard } \\
\text { basalt fiber) (I) }\end{array}$ & 967.5 & 3.56 \\
\hline $\begin{array}{c}\text { Basalt fiber of length 40 MM. (hard } \\
\text { basalt fiber) (II) }\end{array}$ & 968 & 5.16 \\
\hline $\begin{array}{c}\text { Basalt fiber of length 21 MM. (hard } \\
\text { basalt fiber) (III) }\end{array}$ & 980.6 & 4.62 \\
\hline Polypropylene fiber (IV) & 989 & 5.31 \\
\hline Soft basalt fiber of length 20mm. (V) & 1000 & 5.25 \\
\hline Without fiber (VI) & 948.3 & 5.6 \\
\hline
\end{tabular}

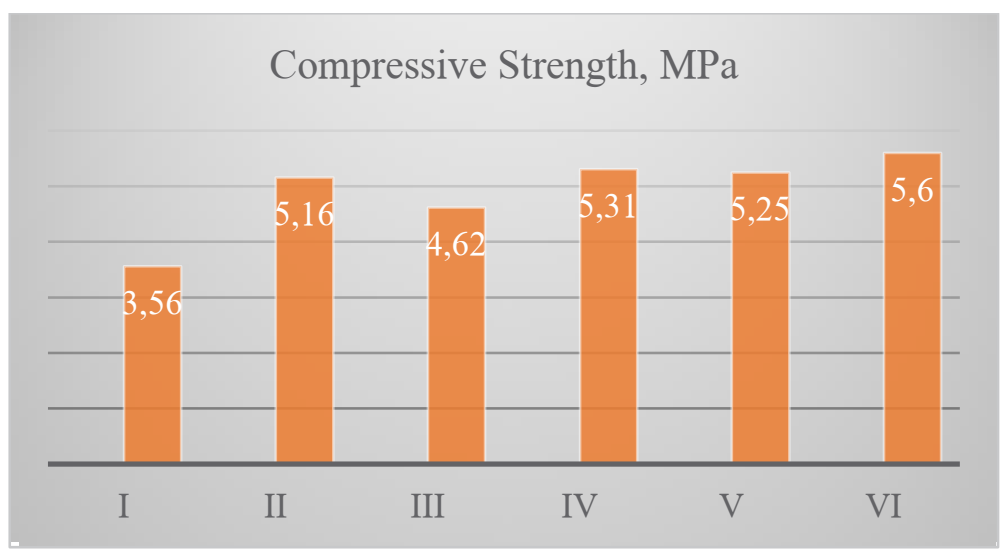

Fig. 7. Compressive strength results of LWEPSC 


\section{Conclusion}

From the experimental results, the following conclusions are made.

1. The smaller the length of hard chopped basalt fiber added in the concrete mix, the more the weight of the concrete cube.

2. Soft basalt fiber produced more weight but gave more compressive strength if compared with the hard basalt fibers.

3. The analysis proved that addition of fiber to lightweight expanded polystyrene concrete reduces the compressive strength of the concrete cube specimens followed by the addition of Polypropylene fiber.

\section{References}

1. L. Grupo, www.bst-betostyrene.com Col Napoles C.P. 03810 Mexico.

2. J. Bolden, T. Abu-Lebdeh, E. Fini, Amer. J. of Environ. Sci. 9 (1),14-24, (2013) doi: 10.3844/ajessp.2013.14.24.

3. M. Barbuta, R. D. Bucur, S. M. Cimpeanu, G. Paraschiv, D. Bucur, Agroecology, Chapter 3, Wastes in Building Materials Industry, INTECH, Croatia, ISBN 978-95351-2130-5, pp. 81-99, (2015)

4. M. Barbuta, R. D. Bucur, A. A. Serbanoiu, C. Helepciuc, S. Scutarasu, A. Burlacu, Combined Effect of Fly Ash and Fibers on Properties of Cement Concrete, The 10th International Conference INTER-ENG 2016 Interdisciplinarity in Engineering, 2016 "Petru Maior" University of Targu-Mureş Romania (2016)

5. J. Sierra-Perez, I. Lopez-Fornies, J. Boschmonart-Rives, X. Gabarrell, J. of Cleaner Prod., 137, 606-616, (2016)

6. J. Kumar Prusty, S. Kumar Patro, S.S. Basarkar, Inter. J. of Sus. Built Environ., 5, 312333, (2016)

7. B. S. Thomas, R. C. Gupta, J. of Cleaner Prod., 113, 86-92, (2016)

8. O.A. Abaza, Z.S. Hussein, J. of Mat. in Civ.Eng., 28 (1), 04015076, (2015)

9. R. Demirboga, K. Abdulkadir, Const. \& Build. Mat. 35, 730-734, (2012)

10. W. C. Tang, H. Z. Cui, M. Wu, Const. \& Build. Mat. 51, 338-343, (2014)

11. A. Kan, R. Demirboga, Cem. \& Conc. Comp., 31, 489-495, (2009)

12. A. Kaya, F. Kar, Const.\& Build. Mat. 102, 572-578, (2016)

13. B. Chen, J. Liu, Const. \& Build. Mat. 21, 7-11, (2007)

14. B. A. Herki, J. M. Khatib, E. M. Negim, Wld. App. Sci. J. 21(9), 1356-1360, (2013)

15. D. S. Babu, K. G. Babu, T. H. Wee, Cem. \& Conc. Res. 35, 1218-1223, (2005)

16. D. H. Minh, L. P. Le, Effect of matrix particle size on EPS lightweight concrete properties. IPICSE-2018, MATEC Web of Conferences 251, 01027 (2018). https://doi.org/10.1051/matecconf/201825101027

17. D. J. Cook, Prec. Conc. 4 (1973)

18. B. Saaba, R.S. Ravindrarajah, Engineering properties of lightweight concrete containing crushed expanded polystyrene waste, Proc. Materials Research Society 1997 Fall Meeting, Boston (1997)

19. H. M. Duc, Tạp chí KHCN Xây dựng 4 (2017)

20. K. G. Babu, D.S. Babu, Cem. \& Conc. Res. (2003)

21. B. A. Herki, J. M. Khatib, E.M. Negim, Wld. App. Sci. J. 21 (9) (2013)

22. K. B. Babu, Cem. \& Conc. Comp., 26 (2004)

23. D. S. Babu, K. G. Babu, T. H. Wee, Cem. \& Conc. Res. (2005)

24. M.A. Ali Sadr Momtazi, A. K. Haggi, H. R. Atigh, Durability of lightweight concrete containing eps in salty exposure conditions. Second International Conference on Sustainable Construction Material and Technologies (2010) 
25. M. Fathi, A. Yousefipour, E. H. Farokhy, Mechanical and physical properties of expanded polystyrene structural concretes containing Micro-silica and Nano-silica. 136 (2017)

26. K. Miled, K. Sab, R. Le Roy, Mech. of Mat. (2007)

27. N. Liu, B. Chen, Const. \& Build. Mat. (2014)

28. GOST 10180-2012. Concretes. Methods for strength determination using reference specimens. Moscow, 2013; 30. 